\title{
MRI compared with low-dose CT scanning in the diagnosis of axial spondyloarthritis
}

\author{
Lusi Ye ${ }^{1} \cdot$ Yuncai Liu ${ }^{2} \cdot$ Qinqin Xiao ${ }^{2} \cdot$ Ledan Dong $^{2} \cdot$ Caiyun Wen $^{2} \cdot$ Zhang Zhang $^{1} \cdot$ Mengmeng Jin $^{1}$. \\ Matthew A. Brown ${ }^{3,4}$ (D) Dan Chen ${ }^{1}$
}

Received: 9 June 2019 / Revised: 9 October 2019 / Accepted: 17 October 2019 / Published online: 3 December 2019

(C) The Author(s) 2019

\begin{abstract}
Objectives To compare the performance of conventional radiography, ldCT, and MRI in the diagnosis of sacroiliitis in suspected axial spondyloarthritis (axSpA).

Methods Patients presenting with $>3$ months chronic back pain were assessed by axSpA-experienced rheumatologists and diagnosed as axSpA or not; axSpA patients were then considered nr-axSpA or AS using plain radiography. NonaxSpA patients were recruited as controls, and divided into non-inflammatory and inflammatory groups on the basis of inflammatory back pain and/or CRP/ESR elevation. Clinical variables, pelvic radiography, sacroiliac joint (SIJ) ldCT, and SIJ MRI were obtained.

Results A total of 121 patients were included and had SIJ radiography and ldCT, of whom 71 additionally had an SIJ MRI. These included 23 non-inflammatory controls, 21 inflammatory controls, 32 nr-axSpA cases, and 45 AS cases. Fourteen of 32 (44\%) nraxSpA patients had positive ldCT scans, 21/24 (88\%) had MRI-BMO, and 11/24 (46\%) had MRI-structural lesions. ldCT had high specificity with only $1 / 23(4 \%)$ non-inflammatory controls being positive. MRI-BMO had the highest sensitivity for nraxSpA, but compared with ldCT lower specificity, with 5/15 (33\%) of non-inflammatory controls being positive, and similar sensitivity for AS (20/22 (91\%) vs 44/44 for ldCT).

Conclusions ldCT identifies evidence of radiographic change in a significant proportion of nr-axSpA cases and is highly specific for axSpA. MRI-BMO lesions are more sensitive than either conventional radiography or MRI-structural assessment for axSpA. The relative position of these imaging modalities in screening for axSpA needs to be reconsidered, also taking into account the costs involved.
\end{abstract}

\section{Key Points}

- IdCT is more sensitive for erosions or sclerosis in axSpA than plain radiography, with $44 \%$ of patients with nr-axSpA having evidence of AS-related sacroiliac joint changes on ldCT.

- MRI-structural lesions are no more sensitive but are less specific for AS than ldCT.

- MRI-BMO is the most sensitive test for nr-axSpA of the modalities tested but is less specific for axSpA than for ldCT.

Keywords axSpA $\cdot$ Conventional radiography $\cdot$ Diagnostics $\cdot$ ldCT $\cdot$ Imaging procedures $\cdot \mathrm{MRI}$

Matthew A. Brown and Dan Chen contributed equally to this work.

Matthew A. Brown

matt.brown@kcl.ac.uk

1 Department of Rheumatology, First Affiliated Hospital, Wenzhou Medical University, Wenzhou 325015, Zhejiang, China
2 Department of Radiology, First Affiliated Hospital, Wenzhou Medical University, Wenzhou 325015, Zhejiang, China

3 Centre for Precision Medicine, First Affiliated Hospital, Wenzhou Medical University, Wenzhou, China

4 Guy's and St Thomas' Hospital NHS Trust and King's College London NIHR Biomedical Research Centre, London, England 


\section{Introduction}

Axial spondyloarthritis (axSpA) and its subtypes nonradiographic axial spondyloarthritis (nr-axSpA) and ankylosing spondylitis (AS) are common causes of chronic back pain. They are characterized by inflammation of the sacroiliac joints, amongst other shared features such as the genetic association with HLA-B27. Diagnosis of the conditions takes into account clinical, genetic, and imaging factors. Evidence of sacroiliitis on imaging modalities especially radiography and MRI is regarded as crucial for diagnosis of axSpA and $\mathrm{AS}$ and is a key component of current classification criteria $[1,2]$. The diagnosis of early axSpA using conventional radiography is particularly challenging, with radiographic changes taking many years on average to develop [3, 4].

The performance of CT scanning to detect sacroiliitis has previously been shown to be better than radiography $[5,6]$. Nonetheless sacroiliitis on CT has not been incorporated into classification criteria until now, perhaps because of the additional radiation exposure typically involved. Recent technological advances have enabled the performance of SIJ CT with the relatively low radiation dose of $0.5 \mathrm{mSv}$, called low-dose CT (ldCT) [7]. This compares with an average global background radiation exposure of $3 \mathrm{mSv}$ annually [8].

Although $\operatorname{ldCT}$ and radiography can identify structural damage, MRI of SIJ has evolved as the most suitable imaging modality for diagnosis and classification of early axSpA including early AS [2], because of its ability to detect inflammatory changes in and around the joints prior to any structural change developing [9]. MRI modalities employed include SPAIR, a T2 fat suppressed technique [10], and diffusionweighted imaging [11]. A standardized definition of structural lesions likely to reflect previous SIJ inflammation was defined by the Canada-Denmark MRI Working Group, employing T1-weighted MRI sequences [2].

In the current study we sought to compare the performance of conventional radiography, ldCT, and MRI, in the diagnosis of AS and nr-axSpA, and their ability to distinguish patients with these conditions from chronic back pain controls.

\section{Methods}

\section{Study population}

Patients with chronic back pain for more than 3-month duration were referred from the Rheumatology Department at the First Affiliated Hospital, Wenzhou Medical University, and assessed by axSpA-experienced rheumatologists. Patients were diagnosed as having axSpA or not on the basis of history, clinical signs, and blood test results only, by the rheumatologists. axSpA cases were then classified as either nr-axSpA or AS cases taking into account the results of the pelvic radiographs only, and not other imaging modalities. Patients diagnosed as not having axSpA by the clinicians were recruited as controls, and were then divided into non-inflammatory and inflammatory control groups on the basis of presence of inflammatory back pain (IBP, defined by the $\mathrm{mNY}$ criteria) and/or CRP/ESR elevation. Analyses were performed both including and excluding subjects with undifferentiated axSpA, peripheral SpA, or psoriatic arthritis. Clinical data including age, gender, disease duration, HLA-B27 status, erythrocyte sedimentation rate $(\mathrm{ESR}, \mathrm{mm} / \mathrm{h})$, and C-reactive protein (CRP, mg/l) were all collected. The study was approved by the institutional ethics committee of the hospital, and written informed consent was provided by all patients.

\section{Radiography technique}

All patients underwent pelvic radiography and SIJ ldCT images, and 71 patients underwent SIJ MRI, with all imaging per patient obtained in a 1-week period. All scans were performed using the same image protocols:

1. Pelvic radiography technique as per [12]: American GE digital X-ray system, $80 \mathrm{kV}$ tube voltage. Oblique sacroiliac view.

2. ldCT scanning technique: GE 64 layer Discovery CT $750 \mathrm{HD}$, acquisition at voltage $120 \mathrm{kV}$, electricity 70 mAs, pitch 0.984 , rotation time $0.8 \mathrm{~s}$, layer thickness 2.5 $\mathrm{mm}$, reconstruction interval $2.5 \mathrm{~mm}$, window width 2000 $\mathrm{Hu}$, window level $350 \mathrm{Hu}$.

3. 3.0 T unit MRI scanning technique: Netherlands Philips Achieva TX 3.0 T, with 8-channel SENSE-XL-Torso coil. Axial T1WI and T2WI and oblique coronal T2WI sequences were performed. In all sequences, the slice thickness was $4 \mathrm{~mm}$, interval $1 \mathrm{~mm}$. AX TSE T2WI with SPAIR, TR $3700 \mathrm{~ms}$, TE $80 \mathrm{~ms}$, FOV $323 \mathrm{~mm} \times 240$ mm, NSA 2; AX TSE T1WI, TR $460 \mathrm{~ms}$, TE $10 \mathrm{~ms}$, FOV $400 \mathrm{~mm} \times 300 \mathrm{~mm}$, NSA 1 ; COR TSE T2WI with SPAIR, TR $3700 \mathrm{~ms}$, TE $80 \mathrm{~ms}$, FOV $400 \mathrm{~mm} \times 300 \mathrm{~mm}$, NSA 2.

\section{Assessment method}

All imaging was read by two expert musculoskeletal radiologists independently. Plain radiographs, CT scans, and MR imaging were read in random order with the radiologists blind to patient affection status. Differences in initial reads were resolved by consensus. For radiography and ldCT, all statistics are based on each SIJ damage grading of 0-4 using the $\mathrm{mNY}$ criteria [1] (as shown in Fig. 1A, B). Definite sacroiliitis was thus defined as bilateral grade 2-4 sacroiliitis or unilateral 3-4 sacroiliitis. For MRI, BMO was defined by the presence of periarticular or subchondral bone marrow edema lesions (Fig. 
Fig. 1 Scoring atlas for seen on plain radiography $(\mathrm{A})$ and $\mathrm{ldCT}$ (B). MRI-BMO and MRIstructural lesions (fat deposition, sclerosis, erosion, and bony ankylosis) (C) a

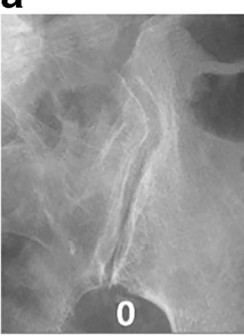

b
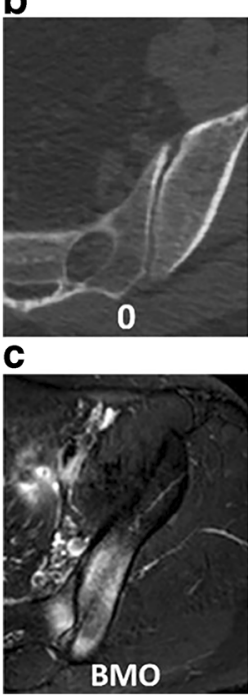

Radiography

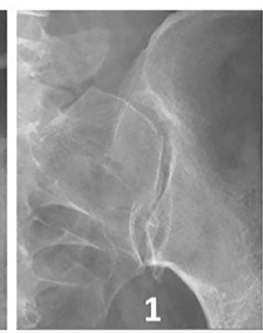

1

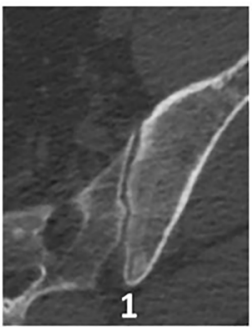

1

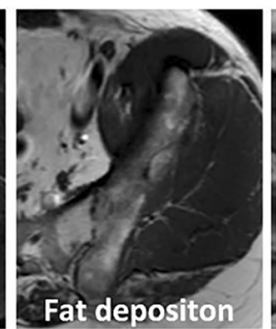

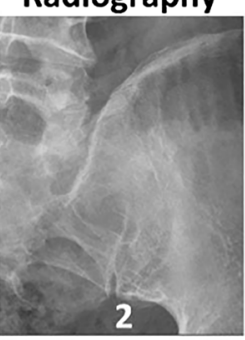

IdCT

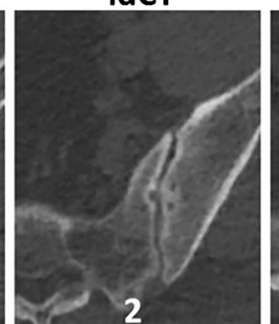

MRI

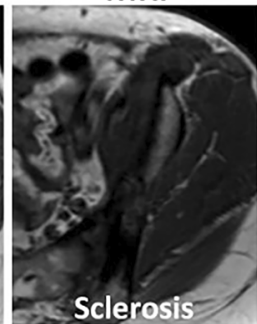

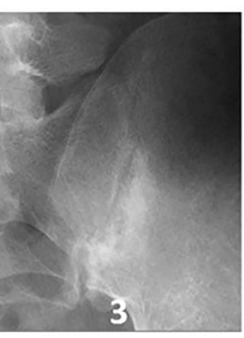
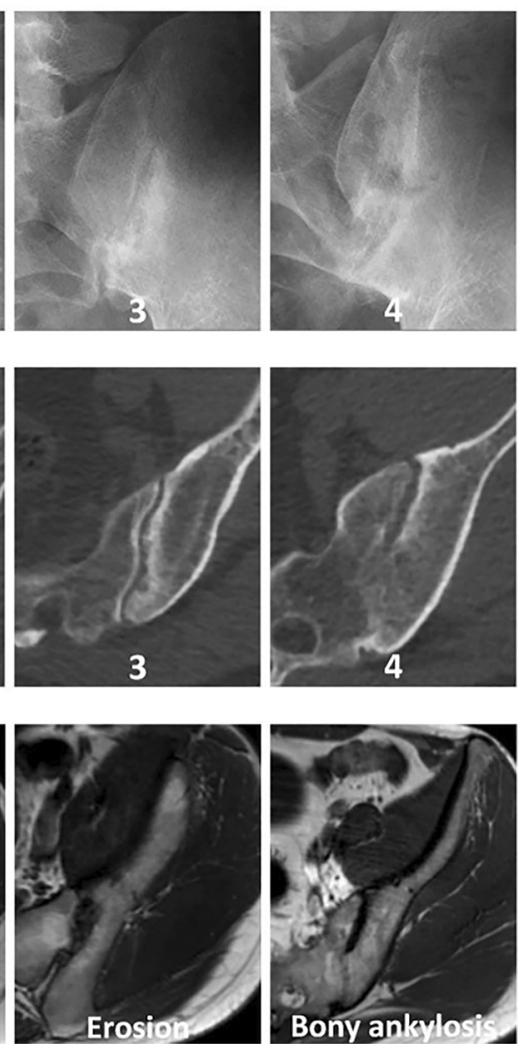

1c) and structural lesions were regarded as fat deposition, sclerosis, erosions, or bony ankylosis [2] (Fig. 1c).

\section{Statistical analysis}

Clinical variables were analyzed using descriptive statistics. All statistics were calculated with SPSS (Version 20.0). Chisquare test or Fisher's exact test was used for categorical data, the McNemar test was used for paired categorical data, and one-way analysis of variance (ANOVA) was used for quantitative data. A $p$ value of $<0.05$ was considered statistically significant.

\section{Results}

\section{Population and clinical statistics}

During the period of 2016-12-26 to 2017-12-31, 121 patients with chronic back pain were recruited. Demographic and clinical details are summarized in Table 1. Comparing the 71 patients that underwent an MRI with the 50 who did not, no differences were observed in gender, age, HLA-B27 carriage, disease duration, ESR, or CRP (Table 2).

Non-inflammatory back pain controls included 23 patients with undifferentiated spondyloarthritis ( 5 cases, 4 performed
MRI), osteoarthritis ( 4 cases, 3 performed MRI), mechanical back pain ( 3 cases, 2 performed MRI), psoriatic arthritis (2 cases, 2 performed MRI), diffuse idiopathic skeletal hyperostosis ( 2 cases, 1 performed MRI), gout ( 2 cases, 0 performed MRI), disc herniation (2 cases, 0 performed MRI), osteitis condensans ilii ( 1 case, 1 performed MRI), palindromic rheumatism ( 1 case, 1 performed MRI), and idiopathic femoral head necrosis ( 1 case, 1 performed MRI). Inflammatory controls included 21 patients with undifferentiated spondyloarthritis ( 6 cases, 4 performed MRI), gout ( 5 cases, 2 performed MRI), Sjogren syndrome ( 3 cases, 2 performed MRI), psoriatic arthritis ( 2 cases, 0 performed MRI), fibromyalgia syndrome ( 1 case, 1 performed MRI), osteitis condensans ilii ( 1 case, 1 performed MRI), peripheral spondyloarthritis ( 1 cases, 0 performed MRI), polymyalgia rheumatic ( 1 case, 0 performed MRI), and palindromic rheumatism ( 1 case, 0 performed MRI).

Most volunteers were male (77/121), with no gender ratio difference between groups, and disease duration was similar between the four groups. The HLA-B27 prevalence was higher in nr-axSpA $(28 / 32=87.5 \%)$ and AS $(42 / 44=$ $95.5 \%$ ) groups than in controls, but was also high overall including in non-inflammatory $(10 / 23=43.5 \%)$ and inflammatory controls $(7 / 18=38.9 \%)$, compared with the HLA-B27 prevalence in the Chinese general population ( 4\%, $[13,14])$. This likely reflects bias amongst patients with chronic back 
Table 1 Baseline demographics and clinical characteristics. Values are given as the numbers or the mean \pm standard deviation

\begin{tabular}{|c|c|c|c|c|c|c|}
\hline & Overall & Non-inflammatory controls & Inflammatory controls & nr-axSpA & AS & $p$ value \\
\hline Number & 121 & 23 & 21 & 32 & 45 & \\
\hline Male/female & $77 / 44$ & $14 / 9$ & $10 / 11$ & $25 / 7$ & $28 / 17$ & 0.15 \\
\hline Duration (months) & $62.3 \pm 82.0$ & $36.2 \pm 38.1$ & $74.4 \pm 91.4$ & $70.5 \pm 105.5$ & $64.2 \pm 74.3$ & 0.38 \\
\hline HLA-B27 (+/-) & $87 / 30$ & $10 / 13$ & $7 / 11$ & $28 / 4$ & $42 / 2$ & 0.000 \\
\hline Age (years) & $43.3 \pm 15.9$ & $46.8 \pm 18.7$ & $55.5 \pm 13.5$ & $37.9 \pm 14.8$ & $39.8 \pm 13.0$ & 0.000 \\
\hline $\operatorname{ESR}(\mathrm{mm} / \mathrm{h})$ & $33.4 \pm 24.6$ & $10.0 \pm 7.0$ & $49.3 \pm 21.9$ & $26.5 \pm 21.4$ & $43.1 \pm 23.3$ & 0.000 \\
\hline CRP (mg/l) & $24.7 \pm 37.7$ & $2.8 \pm 3.0$ & $34.1 \pm 36.6$ & $19.6 \pm 28.8$ & $35.3 \pm 47.4$ & 0.003 \\
\hline
\end{tabular}

pain referred to the rheumatology department, as has been reported in similar studies internationally [2]. nr-axSpA and AS cases had younger age compared with non-inflammatory controls ( $p=0.030$ and 0.066 respectively) and inflammatory controls ( $p=0.000$ and 0.000 respectively). ESR levels were higher in inflammatory controls $(49.3 \pm 21.9)$ and AS $(43.1 \pm$ $23.3)$ than in non-inflammatory controls $(10.0 \pm 7.0, p=$ 0.000 and 0.000 respectively) and $n r-a x S p A(26.5 \pm 21.4, p$ $=0.000$ and 0.001 respectively), higher in nr-axSpA than in non-inflammatory control $(p=0.004)$. AS and inflammatory control had higher CRP than non-inflammatory control (35.3 \pm 47.4 and $34.1 \pm 36.6$ vs $2.8 \pm 3.0, p=0.001$ and 0.005 respectively). The clinical parameters are given in Table 1 .

An effective radiation dose of approximately $1.2 \mathrm{mSv}$ was received per patient for a SIJ $1 \mathrm{dCT}$.

\section{Image results in groups}

The imaging results according to clinical diagnoses are given in Table 3. For conventional radiography, only one $(1 / 23)$ of the non-inflammatory controls and no $(0 / 21)$ inflammatory controls were positive, and none (0/32) of the nr-axSpA and all (44/45) AS cases were positive (as required by the mNYAS criteria). The single non-inflammatory control with positive plain radiography was a 59-year-old HLA-B27-negative female who had osteoarthritis changes in the SIJ on ldCT; therefore, the conventional radiography is considered to be a false positive.

Considering ldCT, 1/23 non-inflammatory controls and 3/ 21 inflammatory controls were positive. The ldCT-positive non-inflammatory control was HLA-B27-negative and negative by MRI, suggesting that it may be a false positive. Of the remaining 3 ldCT-positive inflammatory controls, one had psoriasis and was clinically considered to have axial PsA, and 2 patients (1 HLA-B27-positive) lacked other axSpA criteria, suggesting that they may also be false positives. ldCT detected sacroiliitis in 14/32 (44\%) of nr-axSpA cases, and all AS cases (Table 3 ).

Considering MRI-BMO scans, 5/15 of the noninflammatory controls and 3/10 inflammatory controls were positive, and $3 / 24 \mathrm{nr}-\mathrm{axSpA}$ and 2/22 AS cases were negative. Of the 8 controls positive for MRI-BMO, in 7 cases, conventional radiography and ldCT were negative, and they lacked other axSpA-associated clinical features, suggesting that their MRI-BMO was not due to axSpA. The single remaining patient was an inflammatory control with known PsA, and is thus considered to have axial PsA.

MRI-structural lesions were detected in $4 / 15$ of the noninflammatory controls and 4/10 inflammatory controls, and were negative in 13/24 nr-axSpA and 1/22 AS cases. Five controls carried MRI-structural but not MRI-BMO lesions (3 non-inflammatory controls, 2 inflammatory controls). Three controls had both MRI-BMO and MRI-structural lesions (one each with pSS, osteoarthritis, and fibromyalgia syndrome).

\section{Comparison of imaging modalities}

\section{Capacity of IdCT scanning to ascertain sacroiliitis}

Of 59 axSpA cases considered positive by $\mathrm{ldCT}$, definite sacroiliitis was ascertained on plain radiography in 45 patients (Table 3 and Fig. 2g). Compared with plain radiography, ldCT scans showed a higher sensitivity to detect structural changes indicative of sacroiliitis especially in $\mathrm{nr}$-axSpA (plain radiography vs ldCT respectively; $0 / 32=0 \%$ vs $14 / 32=44 \%$ in nr-

Table 2 Comparison of subjects that had MRI vs those that did not

\begin{tabular}{llllllll}
\hline & Number & $\begin{array}{l}\text { Male/ } \\
\text { female }\end{array}$ & HLA-B27 (+/-) & Age (years) & Duration (months) & ESR (mm/h) & CRP (mg/l) \\
\hline Performed MRI & 71 & $44 / 27$ & $33 / 14$ & $40.7 \pm 16.0$ & $62.2 \pm 82.4$ & $30.7 \pm 25.0$ & $22.6 \pm 40.3$ \\
Did not perform MRI & 50 & $33 / 17$ & $10 / 11$ & $47.1 \pm 15.2$ & $62.4 \pm 82.8$ & $37.2 \pm 23.8$ & $28.2 \pm 34.1$ \\
$p$ value & & 0.65 & 0.40 & 0.55 & 0.85 & 0.85 & 0.66 \\
\hline
\end{tabular}


Table 3 Positive imaging results according to clinical diagnoses

\begin{tabular}{|c|c|c|c|c|}
\hline Diagnosis & Plain radiography & ldCT & MRI-BMO & MRI-structural \\
\hline AS & $45 / 45(100)$ & $45 / 45(100 \%)$ & $20 / 22(91 \%)$ & $21 / 22(95 \%)$ \\
\hline nr-axSpA & $0 / 32(0 \%)$ & $14 / 32(44 \%)$ & $21 / 24(88 \%)$ & $11 / 24(46 \%)$ \\
\hline AS/nr-axSpA & $45 / 77(58 \%)$ & $59 / 77(77 \%)$ & $41 / 46(89 \%)$ & $32 / 46(70 \%)$ \\
\hline Total non-inflammatory controls & $1 / 23(4 \%)$ & $1 / 23(4 \%)$ & $5 / 15(33 \%)$ & $4 / 15(31 \%)$ \\
\hline Total non-inflammatory controls with no SpA & $1 / 16(6 \%)$ & $1 / 16(6 \%)$ & $4 / 9(44 \%)$ & $1 / 9(11 \%)$ \\
\hline Total inflammatory controls & $0 / 21(0 \%)$ & $3 / 21(14 \%)$ & $3 / 10(30 \%)$ & $4 / 10(40 \%)$ \\
\hline Total inflammatory controls with no SpA & $0 / 13(0 \%)$ & $1 / 13(8 \%)$ & $2 / 7(29 \%)$ & $4 / 7(57 \%)$ \\
\hline Total controls & $1 / 44(2 \%)$ & $4 / 44(9 \%)$ & $8 / 25(32 \%)$ & $8 / 25(32 \%)$ \\
\hline Total controls with no SpA & $1 / 29(3 \%)$ & $2 / 29(7 \%)$ & $6 / 16(38 \%)$ & $5 / 16(31 \%)$ \\
\hline
\end{tabular}

$A S$ ankylosing spondylitis, ax $\operatorname{SpA}$ axial spondyloarthritis, $S p A$ spondyloarthritis

$\operatorname{axSpA}, 45 / 45=100 \%$ vs $45 / 45=100 \%$ in $\mathrm{AS}, 45 / 77=58 \%$ vs $59 / 77=77 \%$ in axSpA overall). Specificity for both methods was similarly high (plain radiography vs ldCT respectively; $22 / 23=96 \%$ vs $22 / 23=96 \%$ in noninflammatory controls). ldCT identified more abnormalities in inflammatory controls (plain radiography vs ldCT respectively; $0 / 21=0 \%$ vs $3 / 21=14 \%$ in inflammatory controls). Whether this is due to greater sensitivity in identifying AS cases or these represent imaging false negatives in this group is unclear (see above) (Table 3 and Fig. 2d, g).

$\mathrm{ldCT}$ and conventional radiography results were consistent in 39/44 controls and 63/77 nr-axSpA/AS patients scanned by both plain radiographs and ldCT (Fig. 2d, g), reflecting substantial correlation between the methods (kappa $=0.69$; see Fig. $2 \mathrm{~g}$ ). Considering the pooled controls, no differences were noted in clinical variables including age, gender, CRP, or HLA-B27 status, between conventional radiography and $\mathrm{ldCT}$ concordant or discordant subjects. Considering the $45 \mathrm{nr}-\mathrm{axSpA} / \mathrm{AS}$ cases, statistically significant differences in some parameters were observed in relation to imaging outcome. These include:

- amongst conventional radiography-negative patients, ldCT-positive patients were older $(45.4 \pm 12.7$ vs $32.1 \pm$ 13.9, $p=0.006$ ) than negatives,

- those that were positive for both conventional radiography and ldCT were more likely to be older $(39.8 \pm 13.0 \mathrm{vs}$ $32.1 \pm 13.9, p=0.040)$, and have higher ESR $(43.1 \pm 23.3$ vs $20.8 \pm 18.4, p=0.001$ ) than the 18 that were negative for both imaging modalities (Table 3 ), and

- $\quad$ those that were negative by ldCT had similar HLA-B27 prevalence, but were younger $(32.1 \pm 13.9$ vs $41.1 \pm 13.1$, $p=0.021)$, had lower ESR $(20.8 \pm 18.4$ vs $40.7 \pm 23.5, p$ $=0.03)$, and were more likely to be male $(16 / 18$ vs $37 / 59$, $p=0.036$ ) than positives.

Conventional radiography-negative subjects (cases and controls combined) had lower ESR $(27.6 \pm 23.7$ vs $42.6 \pm$ $23.3, p=0.001)$, lower CRP $(18.7 \pm 29.2$ vs $34.6 \pm 47.1, p$
$=0.001)$, and lower HLA-B27 prevalence $(44 / 72(61.1 \%)$ vs $43 / 45(96.9 \%), p=0.000)$ than positive patients. Conventional radiography-negative $\mathrm{nx}-\mathrm{axSpA} / \mathrm{AS}$ patients had lower ESR $(26.5 \pm 21.4$ vs $43.1 \pm 23.3, p=0.003)$ than positive patients. ldCT-negative subjects (cases and controls) had lower HLA-B27 prevalence (33/55 (62\%) vs 54/62 $(83 \%), p=0.001)$ and shorter disease duration $(24.7 \pm 22.5$ vs $41.1 \pm 23.9, p=0.000$ ) than ldCT-positive too.

\section{Capacity of MRI-BMO scanning to ascertain sacroiliitis}

MRI-BMO had the highest sensitivity for nr-axSpA (88\%), but had lower specificity $(67 \%)$, with lesion of the SIJ on MRI-BMO being observed in up to $32 \%$ of control individuals, and slightly lower sensitivity for AS than $1 \mathrm{dCT}$ (91\% vs $100 \%$ ) (Table 3). MRI-BMO was observed in $41 \mathrm{nr}-\mathrm{axSpA} /$ AS patients, of which $16(37 \%)$ were not detected by $1 \mathrm{dCT}$ (Fig. 2h). However, the ldCT sensitivity in axSpA overall (59/ $77=77 \%)$ compared with MRI-BMO $(41 / 46=89 \%)$ was not so different, driven by its higher sensitivity in AS. 8/25 (32\%) of control subjects were found to have active BMO (specificity 68\%) (Table 3 and Fig. 2e, h).

Consistent MRI-BMO and ldCT reads were seen in 17/26 (65.4\%) and 25/45 (55.6\%) of patients respectively (Fig. 2e, h). Overall, the correlation between MRI-BMO and ldCT was low $(42 / 71$, kappa $=0.23$; Fig. $2 \mathrm{e}, \mathrm{h})$. This was driven primarily by a high proportion of MRI-BMO positivity amongst controls $(8 / 25,32 \%)$, potentially representing MRI-false positives. This observation was true both of the total control dataset, and non-inflammatory or inflammatory controls, whether or not patients had coexistent undifferentiated $\operatorname{axSpA}$, peripheral SpA, or psoriatic arthritis. MRI-BMOnegative cases had lower HLA-B27 prevalence $(13 / 22$ $(59 \%)$ vs $41 / 48(85 \%), p=0.015)$ than MRI-BMO-positive cases. Subjects with both MRI-BMO and ldCT positivity had higher HLA-B27 prevalence (24/24 (100\%) vs 9/17 (53\%), $p$ $=0.000)$ compared with subjects negative for both modalities. Considering only MRI-BMO-positive patients, ldCT-negative 
Fig. 2 Contingency analysis of plain radiography versus lowdose CT (ldCT), ldCT versus MRI-BMO, and ldCT versus MRI-structural lesion. (A) Global positivity as defined for plain radiography and ldCT. (B) Global positivity as defined for ldCT and MRI-BMO. (C) Global positivity as defined for ldCT and MRIstructural lesion. (D) Pooled control positivity as defined for radiography and ldCT. (E) Pooled control positivity as defined for ldCT and MRI-BMO. (F) Pooled control positivity as defined for ldCT and MRI-structural lesion. (G) nr-axSpA/AS positivity as defined for radiography and ldCT. (H) nr-axSpA/AS positivity as defined for ldCT and MRI-BMO. (I) nr-axSpA/AS positivity as defined for ldCT and MRIstructural lesion. K, Cohen's kappa coefficient for agreement of the two modalities; SE, sensitivity; SP, specificity a
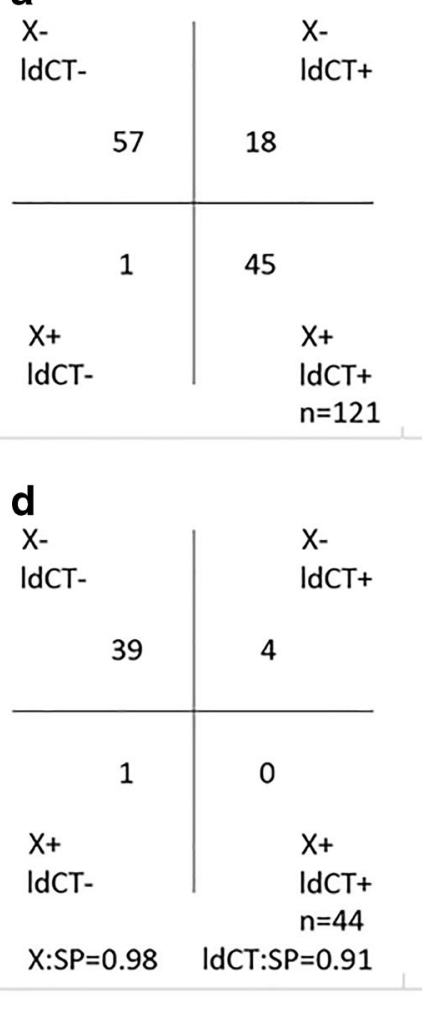

g

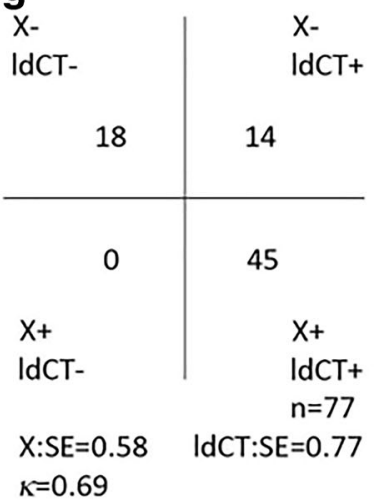

Global patients

b

IdCTBMO-
C

\begin{tabular}{l|l} 
IdCT- & IdCT-
\end{tabular} Lesion- Lesion+
Lesiont

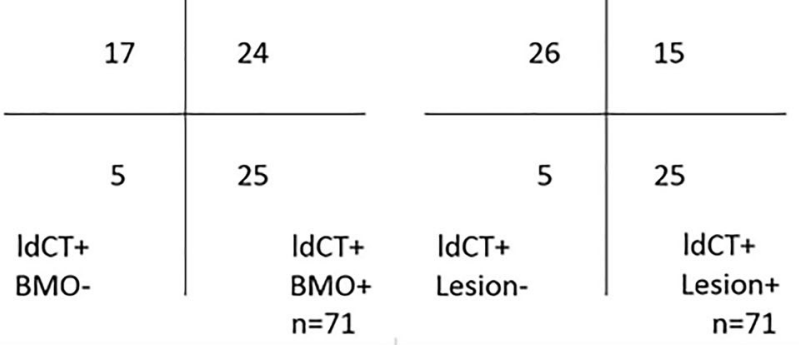

\section{Pooled control}

e IdCTBMO-

\section{f} $\begin{array}{ll}\text { IdCT- } & \text { IdCT- } \\ \text { BMO+ } & \text { Lesion- }\end{array}$
IdCTLesion+

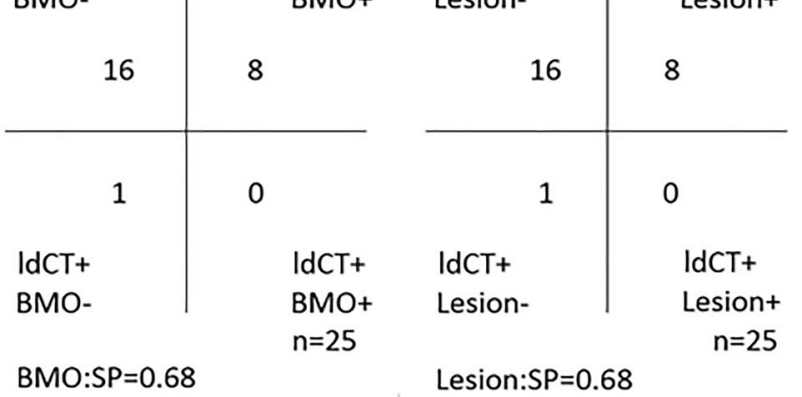

$\mathrm{BMO}: \mathrm{SP}=0.68 \quad$ Lesion $\mathrm{SP}=0.68$

h $\mathrm{nr}-\mathrm{axSpA} / \mathrm{AS}$

harIdCT

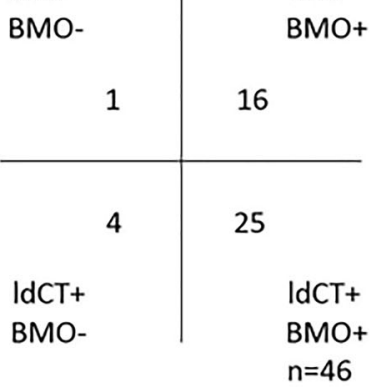
$\mathrm{BMO}: \mathrm{SE}=0.89$ $\kappa=0.23$ i IdCT- IdCTLesion- Lesion+ \begin{tabular}{l|l}
\multicolumn{1}{c|}{10} & 7 \\
\hline 4 & 25 \\
$\begin{array}{l}\text { IdCT+ } \\
\text { Lesion- }\end{array}$ & $\begin{array}{l}\text { IdCT+ } \\
\text { Lesion+ } \\
n=46\end{array}$
\end{tabular}

Lesion:SE $=0.70$ $\kappa=0.45$ patients had lower HLA-B27 prevalence (17/24 vs 24/24, $p=$ $0.009)$ and ESR $(40.5 \pm 27.8$ vs $21.6 \pm 20.2, p=0.011)$ than ldCT positives. Amongst the 46 patients with $\mathrm{nr}-\mathrm{axSpA} / \mathrm{AS}$ screened by both modalities, MRI-BMO-negative patients were more likely to be female (M/F; $1 / 41$ vs $30 / 11, p=$ 0.017 ) than MRI-BMO-positive patients (Table 4). In summary, BMO-positive patients were more likely to carry HLA$\mathrm{B} 27$, be male, and have a raised ESR.

\section{Capacity of MRI-structural lesions scanning to ascertain sacroiliitis}

Of the $32 \mathrm{nr}-\mathrm{axSpA} / \mathrm{AS}$ patients with MRI-structural lesions, $7(22 \%)$ were ldCT-negative. MRI-structural lesions were also seen in $8 / 25(32 \%)$ controls (specificity $=68 \%$ overall, $69 \%$ in non-inflammatory controls, $60 \%$ in inflammatory controls). The sensitivity of MRI-structural lesions was $46 \%(11 / 24)$ in nr-axSpA, and 95\% (21/22) in AS (Table 3 and Fig. 2f, i).

In 16/25 controls and 35/46 cases. the MRI-structural lesions read was consistent with the ldCT read (kappa $=0.45$ ) (Fig. 2f, i). MRI-structural lesion-negative patients had lower HLA-B27 prevalence $(20 / 31$ (65\%) vs $34 / 39(87 \%), p=$ $0.025)$ and lower ESR $(23.7 \pm 20.8$ vs $35.8 \pm 26.8, p=$ $0.047)$ than positive patients. Subjects with both MRIstructural and ldCT positivity had higher HLA-B27 prevalence $(24 / 24(100 \%)$ vs $16 / 26(59 \%), p=0.000)$ and ESR $(42.8 \pm 26.4$ vs $23.9 \pm 21.5, p=0.008)$ compared with subjects negative for both modalities. Considering only MRI-structural 
Table 4 Comparison of clinical variables in imaging modalities

\begin{tabular}{|c|c|c|c|}
\hline & \multicolumn{2}{|c|}{ Comparison object } & \multirow[t]{2}{*}{$p$ value } \\
\hline & X-ray- & X-ray+ & \\
\hline $\operatorname{ESR}(\mathrm{mm} / \mathrm{h})$ & $27.6 \pm 23.7$ & $42.6 \pm 23.3$ & 0.001 \\
\hline CRP (mg/l) & $18.7 \pm 29.2$ & $34.6 \pm 47.1$ & 0.001 \\
\hline HLA-B27 (+/-) & $44 / 28$ & $43 / 2$ & 0.000 \\
\hline nr-axSpA/AS & X-ray- & X-ray+ & \\
\hline \multirow[t]{2}{*}{$\operatorname{ESR}(\mathrm{mm} / \mathrm{h})$} & $26.5 \pm 21.4$ & $43.1 \pm 23.3$ & 0.003 \\
\hline & IdCT- & IdCT+ & \\
\hline HLA-B27 (+/-) & $33 / 22$ & $54 / 8$ & 0.001 \\
\hline Disease duration (months) & $24.7 \pm 22.5$ & $41.1 \pm 23.9$ & 0.000 \\
\hline nr-axSpA/AS & IdCT- & IdCT+ & \\
\hline Age (years) & $32.1 \pm 13.9$ & $41.1 \pm 13.1$ & 0.021 \\
\hline $\mathrm{ESR}(\mathrm{mm} / \mathrm{h})$ & $20.8 \pm 18.4$ & $40.7 \pm 23.5$ & 0.030 \\
\hline \multirow[t]{2}{*}{ Gender (male/female) } & $37 / 22$ & $16 / 2$ & 0.036 \\
\hline & X-IdCT+ & X+ldCT+ & \\
\hline \multirow[t]{2}{*}{ HLA-B27 (+/-) } & $11 / 3$ & $42 / 2$ & 0.050 \\
\hline & X-IdCT- & X-IdCT+ & \\
\hline Age (years) & $32.1 \pm 13.9$ & $45.4 \pm 12.7$ & 0.006 \\
\hline nr-axSpA/AS & X-IdCT- & X+ldCT+ & \\
\hline Age (years) & $32.1 \pm 13.9$ & $39.8 \pm 13.0$ & 0.040 \\
\hline \multirow[t]{2}{*}{$\operatorname{ESR}(\mathrm{mm} / \mathrm{h})$} & $20.8 \pm 18.4$ & $43.1 \pm 23.3$ & 0.001 \\
\hline & BMO- & BMO+ & \\
\hline HLA-B27 (+/-) & $13 / 9$ & $41 / 7$ & 0.015 \\
\hline nr-axSpA/AS & BMO- & BMO+ & \\
\hline \multirow[t]{2}{*}{ Gender (male/female) } & $1 / 4$ & $30 / 11$ & 0.017 \\
\hline & Lesion- & Lesion+ & \\
\hline HLA-B27 (+/-) & $20 / 11$ & $34 / 5$ & 0.025 \\
\hline \multirow[t]{2}{*}{$\operatorname{ESR}(\mathrm{mm} / \mathrm{h})$} & $23.7 \pm 20.8$ & $35.8 \pm 26.8$ & 0.047 \\
\hline & IdCT-BMO- & IdCT+BMO+ & \\
\hline \multirow[t]{2}{*}{ HLA-B27 (+/-) } & $17 / 7$ & $24 / 0$ & 0.009 \\
\hline & IdCT-BMO+ & IdCT+BMO+ & \\
\hline HLA-B27 (+/-) & $9 / 8$ & $24 / 0$ & 0.000 \\
\hline \multirow[t]{2}{*}{$\operatorname{ESR}(\mathrm{mm} / \mathrm{h})$} & $21.6 \pm 20.2$ & $40.5 \pm 27.8$ & 0.011 \\
\hline & IdCT-Lesion+ & $\begin{array}{l}\text { IdCT+ } \\
\quad \text { Lesion+ }\end{array}$ & \\
\hline HLA-B27 (+/-) & $10 / 5$ & $24 / 0$ & 0.005 \\
\hline Disease duration (months) & $26.47 \pm 32.9$ & $80.0 \pm 80.4$ & 0.047 \\
\hline \multirow[t]{2}{*}{$\mathrm{ESR}(\mathrm{mm} / \mathrm{h})$} & $24.6 \pm 24.1$ & $42.8 \pm 26.4$ & 0.024 \\
\hline & IdCT-Lesion- & $\begin{array}{l}\text { IdCT+ } \\
\quad \text { Lesion+ }\end{array}$ & \\
\hline HLA-B27 (+/-) & $16 / 10$ & $24 / 0$ & 0.000 \\
\hline $\operatorname{ESR}(\mathrm{mm} / \mathrm{h})$ & $26.47 \pm 32.9$ & $42.8 \pm 26.4$ & 0.008 \\
\hline nr-axSpA/AS & X-ray $\neq l d C T$ & $X-r a y=l d C T$ & \\
\hline CRP (mg/l) & $15.4 \pm 18.6$ & $31.7 \pm 44.3$ & 0.046 \\
\hline Pooled control & IdCT $\neq$ Lesion & IdCT=Lesion & \\
\hline Gender (male/female) & $2 / 7$ & $11 / 5$ & 0.041 \\
\hline
\end{tabular}

Values are given as counts for dichotomous data or the mean \pm standard deviation for quantitative variables $(\mathrm{Mean} \pm \mathrm{SD})$

ldCT low-dose CT lesion-positive nr-axSpA/AS patients, ldCT-negative patients had lower HLA-B27 prevalence (10/15 vs 24/24, $p=0.005)$, lower ESR $(24.6 \pm 24.1$ vs $42.8 \pm 26.4, p=0.024)$, and lower disease duration $(26.47 \pm 32.9$ vs $80.0 \pm 80.4, p=0.047)$ than positives.

\section{Discussion}

The current study shows that ldCT, relative to conventional radiography, has greater sensitivity and similar specificity in classifying axSpA and chronic back pain patients. In comparison with MRI-BMO, ldCT had lower sensitivity for nraxSpA but similar sensitivity for AS, and higher specificity. In comparison with MRI-structural lesions, it has similar sensitivity for both nr-axSpA and AS, but higher specificity. These findings suggest that $\mathrm{ldCT}$ is a suitable method for screening patients for possible axSpA, either as an initial screening method particularly if access to MR imaging is limited or in cases with negative conventional radiographs where there is high clinical suspicion of disease.

In agreement with previous reports, our study shows that conventional radiography often underestimated the prevalence of sacroiliitis as compared with ldCT scanning. ldCT identified sacroiliitis in $44 \%$ of patients meeting the ASAS classification criteria in whom conventional radiographs were negative. Whether these patients ultimately will develop AS is not clear, but seems likely as this group had high HLA-B27 prevalence. Compared with conventional radiography, there is robust evidence that ldCT scanning will detect more progression of bony changes if covering the whole spine [7, 15], and facilitate the diagnosis of AS in patients while covering SIJ [7]. Our study has shown that erosions can be detected on ldCT of the SIJ early before it can be seen on conventional radiography, and can detect changes in cases where no MRI changes are seen. The specificity of $\mathrm{ldCT}$ is also superior to MRI-BMO. These findings support the argument that ldCT should be used if conventional radiography is unclear, or MRI is unavailable [9] and could be recommended as a reasonable diagnostic imaging modality, even in early sacroiliitis. Inclusion of ldCT to define sacroiliitis would increase the sensitivity of the mNY criteria, particularly in early disease, while maintaining the high specificity of these criteria.

Compared with conventional pelvic radiography techniques, ldCT is still associated with higher radiation exposure, although the dose is not very high. In the current study, the dose employed $1.2 \mathrm{mSv}$ is approximately double that of conventional pelvic radiography $(0.6 \mathrm{mSv})$, similar to a conventional lumbo-sacral spine radiograph (0.5-1.5 mSv), and lower than a nuclear bone scan $(3-5 \mathrm{mSv})$, and less than half the average annual radiation exposure in the UK (2.7 $\mathrm{mSv})$ [16]. Therefore, the radiation dose is not excessive and should not discourage use of ldCT in this setting. 
Our study confirms the high sensitivity for MRI-BMO for active inflammatory lesions even in nr-axSpA. In our study, 10 axSpA patients showed inflammation on MRI-BMO, but without signs of structural lesions on plain radiographs, ldCT, or MRI. Previous studies have reported sensitivity of MRIBMO of around $60-70 \%$ for sacroiliitis detection [17-20]; our research gave the sensitivity of $88 \%$. However, recent studies and this study highlight the lower specificity of MRI-BMO than either conventional radiography or ldCT. Although some studies have suggested a high specificity of active MRI lesions [2], our study supports previous findings of a high incidence of MRI-BMO lesions in particular in chronic back pain controls. For example, Weber and colleagues report BMO lesions in $27 \%$ of nonspecific back pain patients and $22 \%$ of healthy controls [19]. MRI-BMO lesions have also been shown to be common in recreational runners, elite ice hockey players, and women with postpartum back pain fulfilling the ASAS definition of active sacroiliitis and an ASAS-positive MRI of the sacroiliac joints can also occur in runners, women with postpartum back, and even healthy volunteers [21, 22]. Our study therefore lends further support to the contention that "Not everything that glisters is gold (standard)" [23], as MR imaging is associated with significant false positive rates in assessment of chronic back pain.

Consistent with previous publications, our study confirms that MRI-structural lesions have modest specificity [19, 24, 25], and that their sensitivity was no greater than that of ldCT. There appears no consistent benefit of adding MRI-structural erosions to the definition of axSpA.

To our knowledge, it is the first study to have controlled data on whether ldCT may have higher sensitivity to detect SIJ erosions compared with MRI. A recent report suggested that ldCT may be a brilliant new chapter for spondyloarthritis [26-29]. Our study supports this view, indicating that $\mathrm{ldCT}$ was the best imaging modality for assessment of structural changes, whereas inflammation was best identified by MRI-BMO. Inclusion of ldCT positivity in the $\mathrm{mNY}$ criteria would significantly increase their sensitivity for the diagnosis of AS, and in imaging positive ASAS-positive nr-axSpA increase the specificity of the criteria. Further studies appear warranted about the relative utility of these modalities, and their position in diagnostic algorithms and classification criteria for axSpA.

Acknowledgments We thank Yan Zhou, Yongji Li, and Peirong Chen for assistance.

\section{Compliance with ethical standards}

The study was approved by the institutional ethics committee of the hospital, and written informed consent was provided by all patients.

Disclosures None.
Open Access This article is distributed under the terms of the Creative Commons Attribution 4.0 International License (http:// creativecommons.org/licenses/by/4.0/), which permits unrestricted use, distribution, and reproduction in any medium, provided you give appropriate credit to the original author(s) and the source, provide a link to the Creative Commons license, and indicate if changes were made.

\section{References}

1. van der Linden S, Valkenburg HA, Cats A (1984) Evaluation of diagnostic criteria for ankylosing spondylitis. A proposal for modification of the New York criteria. Arthritis Rheum 27(4):361-368

2. Rudwaleit M, Landewe R, van der Heijde D, Listing J, Brandt J, Braun J, Burgos-Vargas R, Collantes-Estevez E, Davis J, Dijkmans B, Dougados M, Emery P, van der Horst-Bruinsma IE, Inman R, Khan MA, Leirisalo-Repo M, van der Linden S, Maksymowych WP, Mielants H, Olivieri I, Sturrock R, de Vlam K, Sieper J (2009) The development of Assessment of SpondyloArthritis international Society classification criteria for axial spondyloarthritis (part I): classification of paper patients by expert opinion including uncertainty appraisal. Ann Rheum Dis 68(6):770-776. https://doi.org/10. 1136/ard.2009.108217

3. Mau W, Zeidler H, Mau R, Majewski A, Freyschmidt J, Deicher H (1987) Outcome of possible ankylosing spondylitis in a 10 years' follow-up study. Clin Rheumatol 6(Suppl 2):60-66

4. Bennett AN, McGonagle D, O'Connor P, Hensor EM, Sivera F, Coates LC, Emery P, Marzo-Ortega H (2008) Severity of baseline magnetic resonance imaging-evident sacroiliitis and HLA-B27 status in early inflammatory back pain predict radiographically evident ankylosing spondylitis at eight years. Arthritis Rheum 58(11): 3413-3418. https://doi.org/10.1002/art.24024

5. Devauchelle-Pensec V, D’Agostino MA, Marion J, Lapierre M, Jousse-Joulin S, Colin D, Chary-Valckenaere I, Marcelli C, Loeuille D, Aegerter P, Guis S, Gaudin P, Breban M, Saraux A, Study Group of S (2012) Computed tomography scanning facilitates the diagnosis of sacroiliitis in patients with suspected spondylarthritis: results of a prospective multicenter French cohort study. Arthritis Rheum 64(5):1412-1419. https://doi.org/10.1002/ art.33466

6. Fam AG, Rubenstein JD, Chin-Sang H, Leung FY (1985) Computed tomography in the diagnosis of early ankylosing spondylitis. Arthritis Rheum 28(8):930-937

7. Diekhoff T, Hermann KG, Greese J, Schwenke C, Poddubnyy D, Hamm B, Sieper J (2017) Comparison of MRI with radiography for detecting structural lesions of the sacroiliac joint using CT as standard of reference: results from the SIMACT study. Ann Rheum Dis 76(9):1502-1508. https://doi.org/10.1136/annrheumdis-2016210640

8. (2008) UNSCotEoAR (2010) Sources and effects of ionizing radiation. United Nations, New York

9. Mandl P, Navarro-Compan V, Terslev L, Aegerter P, van der Heijde D, D'Agostino MA, Baraliakos X, Pedersen SJ, Jurik AG, Naredo E, Schueller-Weidekamm C, Weber U, Wick MC, Bakker PA, Filippucci E, Conaghan PG, Rudwaleit M, Schett G, Sieper J, Tarp S, Marzo-Ortega H, Ostergaard M, European League Against R (2015) EULAR recommendations for the use of imaging in the diagnosis and management of spondyloarthritis in clinical practice. Ann Rheum Dis 74(7):1327-1339. https://doi.org/10. 1136/annrheumdis-2014-206971

10. Dalto VF, Assad RL, Crema MD, Louzada-Junior P, NogueiraBarbosa MH (2017) MRI assessment of bone marrow oedema in the sacroiliac joints of patients with spondyloarthritis: is the SPAIR 
T2w technique comparable to STIR? Eur Radiol 27(9):3669-3676. https://doi.org/10.1007/s00330-017-4746-7

11. Bradbury LA, Hollis KA, Gautier B, Shankaranarayana S, Robinson PC, Saad N, Le Cao KA, Brown MA (2018) Diffusionweighted imaging is a sensitive and specific magnetic resonance sequence in the diagnosis of ankylosing spondylitis. J Rheumatol. https://doi.org/10.3899/jrheum.170312

12. Le Goff P, Saraux A, Baron D (2001) Radiographic diagnosis of sacroiliitis-are sacroiliac views really better? J Rheumatol 28(1): 212-214

13. Liu Y, Jiang L, Cai Q, Danoy P, Barnardo MC, Brown MA, Xu H (2010) Predominant association of HLA-B*2704 with ankylosing spondylitis in Chinese Han patients. Tissue Antigens 75(1):61-64. https://doi.org/10.1111/j.1399-0039.2009.01379.x

14. Yi L, Wang J, Guo X, Espitia MG, Chen E, Assassi S, Jin L, Zou H, Reveille JD, Zhou X (2013) Profiling of HLA-B alleles for association studies with ankylosing spondylitis in the Chinese population. Open Rheumatol J 7:51-54. https://doi.org/10.2174/ 1874312920130628001

15. de Bruin F, de Koning A, van den Berg R, Baraliakos X, Braun J, Ramiro S, van Gaalen FA, Reijnierse M, van der Heijde D (2018) Development of the CT Syndesmophyte Score (CTSS) in patients with ankylosing spondylitis: data from the SIAS cohort. Ann Rheum Dis 77(3):371-377. https://doi.org/10.1136/annrheumdis2017-212553

16. PH. E (2011) Ionising radiation: dose comparisons.

17. Oostveen J, Prevo R, den Boer J, van de Laar M (1999) Early detection of sacroiliitis on magnetic resonance imaging and subsequent development of sacroiliitis on plain radiography. A prospective, longitudinal study. J Rheumatol 26(9):1953-1958

18. Puhakka KB, Jurik AG, Egund N, Schiottz-Christensen B, Stengaard-Pedersen K, van Overeem HG, Christiansen JV (2003) Imaging of sacroiliitis in early seronegative spondylarthropathy. Assessment of abnormalities by MR in comparison with radiography and CT. Acta Radiol 44(2):218-229

19. Weber U, Lambert RG, Ostergaard M, Hodler J, Pedersen SJ, Maksymowych WP (2010) The diagnostic utility of magnetic resonance imaging in spondylarthritis: an international multicenter evaluation of one hundred eighty-seven subjects. Arthritis Rheum 62(10):3048-3058. https://doi.org/10.1002/art.27571

20. Wittram C, Whitehouse GH, Williams JW, Bucknall RC (1996) A comparison of MR and CT in suspected sacroiliitis. J Comput Assist Tomogr 20(1):68-72

21. de Winter J, de Hooge M, van de Sande M, de Jong H, van Hoeven L, de Koning A, Berg IJ, Ramonda R, Baeten D, van der Heijde D, Weel A, Landewe R (2018) Magnetic resonance imaging of the sacroiliac joints indicating sacroiliitis according to the Assessment of SpondyloArthritis international Society Definition in healthy individuals, runners, and women with postpartum back pain. Arthritis Rheumatol 70(7):1042-1048. https://doi.org/10.1002/art.40475

22. Weber U, Jurik AG, Zejden A, Larsen E, Jorgensen SH, Rufibach K, Schioldan C, Schmidt-Olsen S (2018) Frequency and anatomic distribution of magnetic resonance imaging features in the sacroiliac joints of young athletes: exploring "background noise" toward a data-driven definition of sacroiliitis in early spondyloarthritis. Arthritis Rheumatol 70(5):736-745. https://doi.org/10.1002/art. 40429

23. Lukas C, Cyteval C, Dougados M, Weber U (2018) MRI for diagnosis of axial spondyloarthritis: major advance with critical limitations 'Not everything that glisters is gold (standard)'. RMD Open 4(1):e000586. https://doi.org/10.1136/rmdopen-2017-000586

24. Braun J, Baraliakos X, Golder W, Hermann KG, Listing J, Brandt J, Rudwaleit M, Zuehlsdorf S, Bollow M, Sieper J, van der Heijde D (2004) Analysing chronic spinal changes in ankylosing spondylitis: a systematic comparison of conventional $\mathrm{x}$ rays with magnetic resonance imaging using established and new scoring systems. Ann Rheum Dis 63(9):1046-1055. https://doi.org/10.1136/ard.2003. 019968

25. Weber U, Pedersen SJ, Ostergaard M, Rufibach K, Lambert RG, Maksymowych WP (2012) Can erosions on MRI of the sacroiliac joints be reliably detected in patients with ankylosing spondylitis? A cross-sectional study. Arthritis Res Ther 14(3):R124. https://doi. org/10.1186/ar3854

26. Maksymowych WP, Lambert RG (2018) Spondyloarthritis: lowdose CT for spondyloarthritis - a brilliant new chapter? Nat Rev Rheumatol 14(3):130-131. https://doi.org/10.1038/nrrheum.2018. 4

27. Tan S, Ward MM (2018) Computed tomography in axial spondyloarthritis. Curr Opin Rheumatol 30(4):334-339. https:/ doi.org/10.1097/BOR.0000000000000507

28. Poddubnyy D (2017) Radiographic evaluation of sacroiliac joints in axial spondyloarthritis - still worth performing? J Rheumatol 44(1): 1-3. https://doi.org/10.3899/jrheum.161232

29. Kucybala I, Urbanik A, Wojciechowski W (2018) Radiologic approach to axial spondyloarthritis: where are we now and where are we heading? Rheumatol Int 38(10):1753-1762. https://doi.org/10. 1007/s00296-018-4130-1

Publisher's note Springer Nature remains neutral with regard to jurisdictional claims in published maps and institutional affiliations. 